\title{
Cuando la potasa genera patrimonio. Dos modelos contrapuestos: Súria y Cardona (Barcelona)
}

Andri Tsiouti. Universidad Politécnica de Cataluña, Barcelona, España.

RESUMEN | Se examinan los factores que inciden para que ciertos paisajes mineros, a pesar del rechazo que generan por ser fuente de contaminación y de conflictos sociales, se acaben revalorizando. Se analizan dos casos de estudio en la provincia de Barcelona: el conjunto minero de Cardona y la mina de Súria, dos explotaciones cercanas, ambas de potasa, pero con características muy diversas. La clausura del yacimiento de Cardona impulsó la creación del Parque Cultural de la Montaña de Sal, que aspira a generar nueva riqueza a través de la valorización del legado geológico y minero. Al mismo tiempo, en Súria, la multinacional Iberpotash sigue explotando potasas y contaminando gravemente la zona, con un claro peligro para la salud. Esta situación contradictoria constituye el objeto de estudio de este artículo. Partiendo de dos paisajes de explotación de la potasa, pretende descubrir los factores que condicionan el rechazo o valorización patrimonial del paisaje minero.

PALABRAS CLAVE | gestión territorial, medioambiente, patrimonio.

ABSTRACT | We examine the reasons why certain mining landscapes, despite being rejected for being sources of contamination and social conflicts, regain value. It focuses on two potash mining sites in the province of Barcelona: the Cardona Salt Mountain and the mining complex of Suria, which present considerable differences despite their proximity. The closure of the Cardona mine stimulated the creation of the Salt Mountain Cultural Park, a touristic and cultural initiative that aims to create new wealth through the valorisation of the mining and geological legacy. At the same time, in the nearby municipality of Suria, the multinational company Iberpotash continues exploiting a potash mine, causing serious pollution and public health risks. This contradiction constitutes the focus of this study. Starting from two potash landscapes, the purpose is to identify the conditioning factors for the rejection or valorisation of mining landscapes as cultural heritage.

KEYWORDS | territorial management, environment, heritage.

Recibido el 3 de abril de 2020, aprobado el 8 de junio de 2020.

E-mail: andri.tsiouti@upc.edu 


\section{Introducción}

A pesar de la necesidad de intervenciones urgentes para recuperar terrenos contaminados, la existencia de valores patrimoniales en las explotaciones mineras exige compatibilizar aquellas intervenciones con la puesta en valor de los recursos culturales. Con esta hipótesis como punto de partida, el presente artículo indaga sobre los factores que inciden para que ciertos paisajes mineros devengan exponentes de la cultura local y de la memoria colectiva, a objeto de contribuir al desarrollo socioeconómico de dicho ámbito. Los recursos mineros no reciben aún la atención que disfrutan otros tipos de patrimonio, ya sea por su condición de ordinario y cotidiano, incluso degradado, debido al abandono una vez agotada la extracción, o por resultar la minería una actividad generadora de impactos sobre el medioambiente y la salud humana y de conflictos sociales como consecuencia de las duras condiciones de trabajo que les son propias.

Durante los años sesenta y setenta, la creciente preocupación por la incidencia de la actividad minera dio lugar al diseño de un marco normativo con medidas para controlarla, primero en Europa y poco después en España. Esto impulsó prácticas restauradoras en todo el país. Sin embargo, la urgencia de atenuar las graves repercusiones de la contaminación hizo que las intervenciones se centraran esencialmente en la recuperación de los terrenos afectados. Los valores patrimoniales de las explotaciones pasan a segundo plano, y a menudo se olvidan u ocasionan su pérdida. Por la otra parte, crece la conciencia de su significado como lugares de memoria e identidad y de su potencial para ofrecer alternativas de desarrollo en las antiguas comarcas mineras, que pierden su principal actividad productiva. Así pues, a finales de los años setenta aparecen las primeras iniciativas de puesta en valor en todo el país, que crecen paulatinamente.

A partir de estas consideraciones, valoraremos cómo la corrección de los impactos topográficos o ambientales se pueda compatibilizar con la preservación de los valores culturales del paisaje minero. Entre la inmensa cantidad y heterogeneidad de explotaciones mineras, nos centramos en el análisis de algunas que presentan un elevado grado de contaminación, lo que supone complejidad ańadida en el momento de intervenir en las mismas. Aspiramos a desvelar los factores que puedan incidir para que las debilidades de estos lugares se conviertan en un valor; que las singularidades del paisaje minero como testimonio del pasado y de la fisonomía particular de cada sitio se aprovechen para impulsar un nuevo desarrollo.

La comarca del Bages, en la provincia de Barcelona, es el principal territorio de Espańa donde se explota la potasa, material obtenido a partir de la silvita (KCL), que principalmente se usa como fertilizante agrícola (Roig et al., 2017). Esta actividad arrancó en el primer cuarto del siglo xx, cuando el ingeniero Emilio Viader Solé y su socio capitalista Ren Macary localizaron en 1912 el pequeño yacimiento de Súria. Una vez obtenidas las primeras concesiones, empezó en 1920 la explotación de dicha mina, seguida por las de Cardona (1931), Sallent (1932) y Balsareny (1948) (Llurdés, 2017), construyéndose una línea férrea para el transporte de la potasa hacia el puerto de Barcelona, línea que sigue funcionando hasta hoy con un convoy diario. Cabe señalar que la actividad salinera en el Bages es muy antigua, pues se 
lleva a cabo ininterrumpidamente en Cardona desde el 4000 a.C., para la obtención de sal gema o sal común. Sin embargo, la explotación masiva de la potasa marcó una nueva etapa en la comarca. Desde mediados del siglo xix Alemania tiene la primacía en la producción de potasa, y su descubrimiento en Cataluña significa una fuente de riqueza fundamental (Galera, 2005), que se traduce en puestos de trabajo, crecimiento demográfico y notables beneficios.

En 1990 cerró la mina de Cardona por razones de rentabilidad y seguridad laboral, habiendo llegado las explotaciones a la máxima profundidad. Se abandonó un complejo sistema de pozos, galerías, máquinas e instalaciones. Al perder su principal actividad, el municipio sufrió una grave crisis socioeconómica, que se tradujo en pérdida de puestos de trabajo, un paisaje profundamente alterado por la extracción y la presencia de dos grandes escombreras que contaminaban las aguas y los terrenos del Valle Salino de Cardona.

Varias circunstancias han incidido para que el legado minero de la Montaña de Sal se empiece a percibir como recurso patrimonial y se intente ponerlo en valor, como alternativa a la crisis minera. La larga tradición salinera, tan arraigada en la cultura e identidad local; la singularidad del afloramiento salino, con sus extraordinarias formaciones geológicas; la existencia de otros atractivos culturales y naturales; la relativamente baja incidencia de los impactos ambientales de la potasa en Cardona; el arraigo de la empresa explotadora en el lugar; la capacidad de las administraciones locales como emprendedores del proyecto y el acceso a subvenciones, favorecieron la creación del Parque Cultural de la Montaña de Sal en 1997, que ha recuperado parte del patrimonio minero para generar un nuevo desarrollo sobre la base del turismo cultural (Figura 1).

Figura I | La Montaña de Sal de Cardona; vista exterior y acceso a la mina

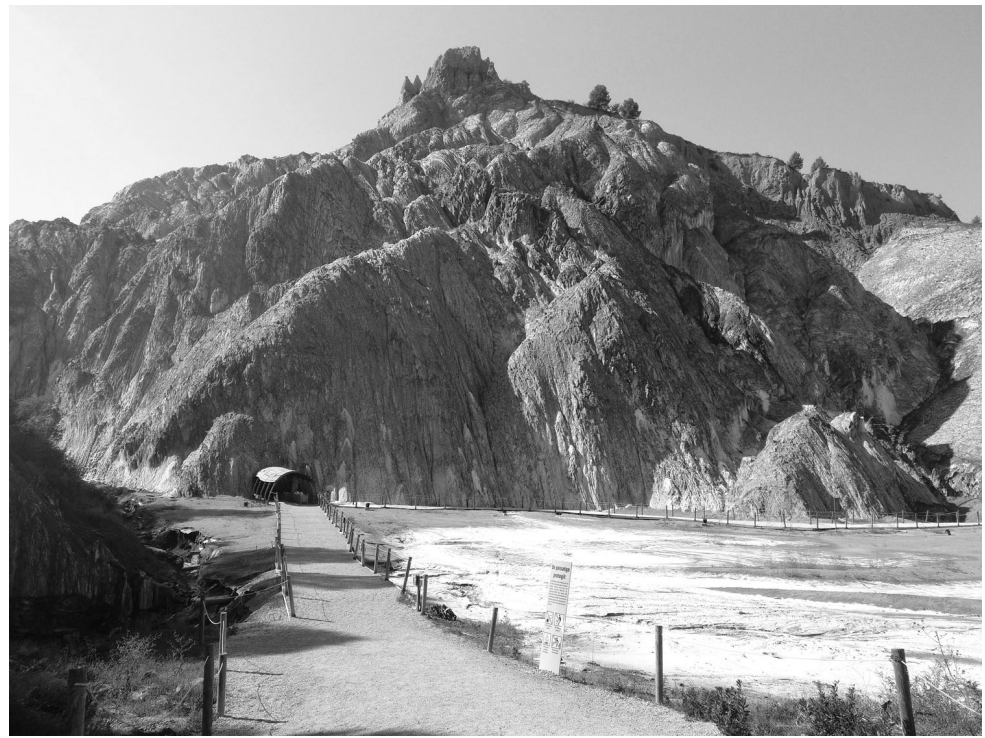

FUENTE: ARCHIVO PROPIO 
En el vecino municipio de Súria, la explotación de la potasa sigue hasta nuestros días con un ritmo frenético, siendo una de las reservas potásicas más importantes de Europa Occidental. Iberpotash, uno de los mayores productores mundiales, desarrolla una intensa actividad, generando graves problemas ambientales y de salud pública. El principal problema derivado de la explotación de la potasa es la generación de gran cantidad de residuos, que con los años forman escombreras de grandes dimensiones. Considerando que para cada tonelada de potasa se obtienen tres de halita residual (Martínez, 2018), puede imaginarse la cantidad de residuos producidos. El paisaje del entorno, pues, se caracteriza por grandes montañas artificiales con un notable impacto visual (Figura 2). Las gigantescas escombreras de Sallent (Cogulló) y de Súria (Fusteret), destacan desde la carretera de acceso, habiendo sido abandonada la primera sin tratamiento, tras el cierre reciente de la mina, mientras la segunda crece de manera acelerada, a la par que la empresa amplía su actividad productiva. Al margen de las repercusiones paisajísticas, la mala gestión de los residuos salinos y la ausencia de medidas de protección ambiental generan serios impactos. Debido a que las escombreras no se impermeabilizan, los residuos provocan la salinización de los ríos Llobregat y Cardener, e impiden su uso doméstico y para el riego (Fernández, 2010). Además, la extracción provoca en ciertos casos la subsidencia de los terrenos, con grave riesgo de hundimientos, como ha sucedido ya en un barrio de Sallent, forzando su abandono (Martinez \& Waldron, 2015). A pesar de que las repercusiones de la potasa en la comarca son más que conocidas, ni las denuncias de los grupos ambientalistas locales, ni la legislación minera, parecen resultar suficientes para controlar la actividad de la multinacional. Los vacíos legales y su capacidad económica le permiten evadir sus responsabilidades y evitar las indemnizaciones que debiera afrontar.

Estas circunstancias hacen que dos territorios mineros tan próximos, Cardona y Súria, vinculados a la explotación de la potasa, se acaben percibiendo de forma totalmente diferente. Cardona consigue superar el rechazo derivado de la crisis socioeconómica y ambiental tras el cierre de la mina, rescatando su patrimonio milenario. Defiende su memoria y cultura salinera, con su Montańa de Sal, uno de los equipamientos culturales más visitados de Cataluña. La mina de Súria, en cambio, transmite una imagen ambivalente. Por un lado, ofrece empleo a miles de personas, pero por otro constituye la principal fuente de contaminación de los cursos fluviales, con serias afecciones al medioambiente y a la población. Esta contradicción constituye el objeto del presente estudio. Nos centramos en dos casos que, aunque comparten el mismo ámbito geográfico y tipo de explotación, evolucionan de manera muy diferente. Nos apoyamos en fuentes primarias, y específicamente, en datos históricos sobre la evolución de las dos explotaciones; en estudios sobre la defensa del patrimonio cultural y minero, investigaciones de especialistas, datos recuperados por las autoridades y publicaciones de prensa en materia de medioambiente.

El trabajo se divide en tres partes. La primera se centra en Cardona. Destaca las singularidades de la misma en su conjunto y el valor de su Montańa de Sal, la evolución de la explotación minera hasta su finalización, la puesta en marcha del 
proyecto del Parque Cultural y las circunstancias que la favorecen, así como los resultados que genera para la comunidad local.

La segunda parte se dedica a la explotación de la potasa en Súria, a través de un análisis comparativo que pretende identificar las diferencias de este caso con el anterior, y así llegar a revelar los factores que inciden para que evolucionen de manera tan distinta. El estudio finaliza con algunas conclusiones que extraemos a partir de la contraposición de los dos ejemplos escogidos, con el fin de deducir algunas lecciones sobre los factores que inciden para que algunos paisajes mineros, a pesar del daño que provocan, se acaben valorizando.

\section{FIGURA 2 | La escombrera de Súria}

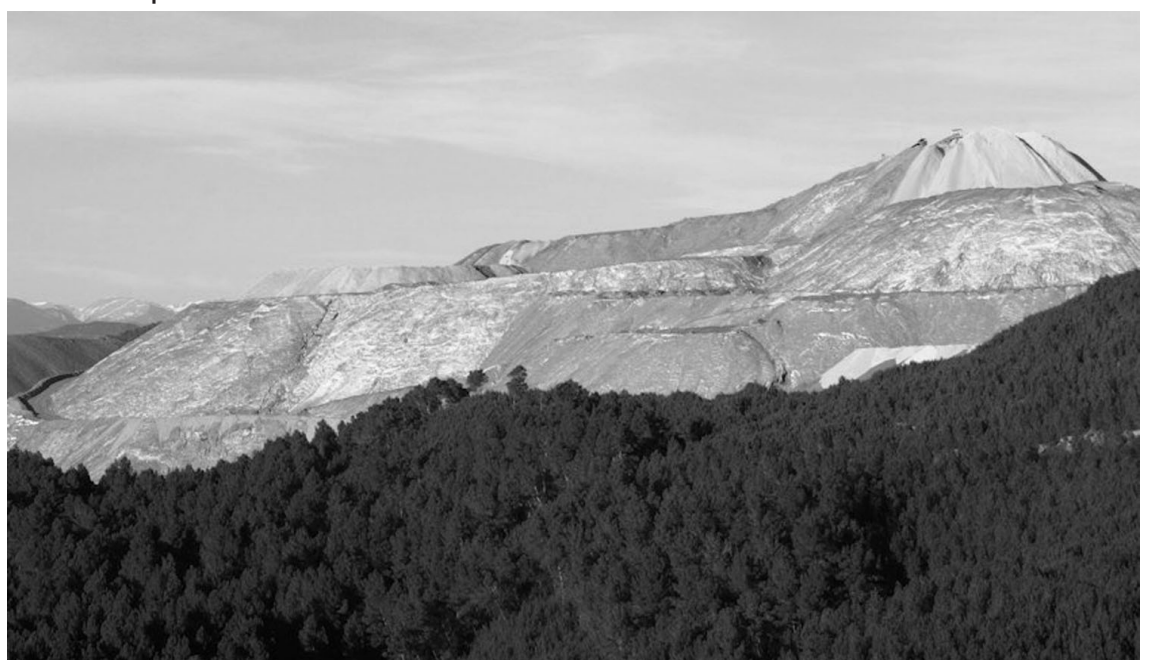

FUENTE: EL MEDI NATURAL DEL BAGES. HTTPS://ICHN2.IEC.CAT/BAGES/IMPACTES/IMATGES\%2OGRANS/ CSURIA.HTM

\section{Cardona: el impulso del Parque Cultural en un contexto salinero}

En Cardona, a diferencia de los otros tres municipios afectados, la minería es una actividad de larga tradición. La pequeña ciudad se caracteriza por la explotación ininterrumpida de sal gema desde la época neolítica (4500-4200 a.C.), siendo la primera explotación europea de sal minera (Fíguls et al., 2013). En el yacimiento minero del Valle Salino, que ocupa unas 130 hectáreas, aflora el anticlinado de la Montaña de Sal, de estructura diapírica, con impresionantes formaciones geológicas, único en el mundo, con aspecto cristalizado y multicolor por el exterior y un conjunto interior de concavidades, cuevas y bóvedas naturales policromadas, formado desde hace miles de años. La Montańa de Sal es un patrimonio natural y cultural singular; constituye una de las riquezas más significativas del patrimonio geológico de Cataluña y, junto con el valle salino que la rodea, está incluida desde 1992 en el Plan de Espacios de Interés Natural (PEIN) de Cataluńa como paraje natural protegido. La importancia que tiene la sal como bien colectivo convierte 
su extracción y distribución en un referente de la vida cotidiana de la población, que la ha aprovechado durante siglos (Llurdés, 2017), consolidando una cultura e identidad salinera. La Carta de Población de Cardona, una de las más antiguas de Europa, concedida por el conde Borrell en 986, otorga a los habitantes el derecho de obtener sal para su propio uso (Riera et al., 1990).

Cabe señalar que Cardona presenta una particularidad que la distingue de los municipios vecinos. Es una ciudad condal en la cabecera del Bages que, gracias a la riqueza del Valle Salino y la posición estratégica para la extracción y comercialización de la sal hacia Europa, mantiene desde bien temprano un protagonismo sociopolítico de primera línea. Sus gobernadores, que pasan de ser vizcondes (siglo X) a condes (siglo XI) y finalmente duques (siglo Xv), han tenido siempre un poder e influencia relevantes (Riera et al., 1990). El majestuoso castillo, situado en el pico más alto de la villa, representa este dominio y es la última fortaleza que cae frente a las tropas borbónicas en 1714, convirtiéndose en un símbolo de resistencia en la comarca (Figura 3). Tanto el castillo, uno de los más notables de Cataluńa, declarado monumento nacional, como la villa antigua que lo rodea, el asentamiento de la población minera, los restos de murallas y capillas o las masías esparcidas por los alrededores, constituyen un conjunto de alto valor cultural. El rico patrimonio natural y cultural hace que Cardona esté preparada para acoger el proyecto del Parque de la Montańa de Sal, ya que la presencia de otros recursos favorece la atracción de visitantes y la convierte en uno de los pocos municipios del Bages con relevante potencial turístico.

\section{FIgURA 3 | La villa de Cardona y su castillo}

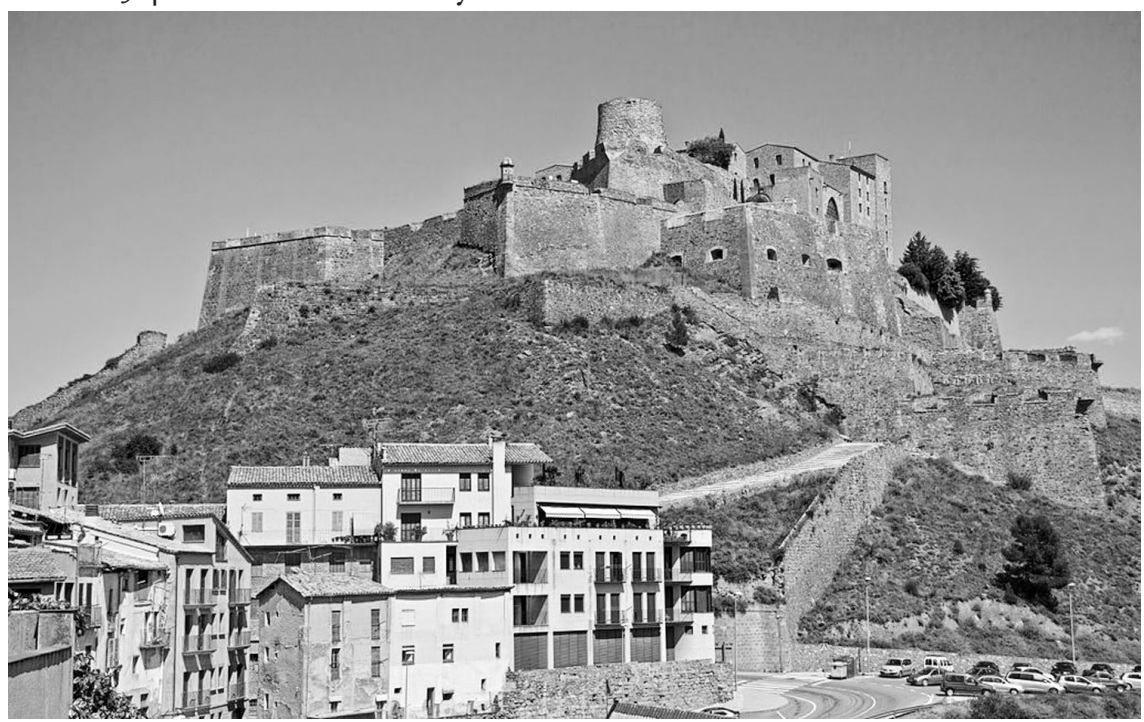

FUENTE: WIKIPEDIA. HTTPS://ES.WIKIPEDIA.ORG/WIKI/CARDONA 
Aunque Súria presenta interés por la fisonomía medieval de su núcleo antiguo, la línea férrea y la estación del tren minero de principios del siglo o algunos lugares de interés histórico o natural, esto no resulta suficiente para impulsar un desarrollo turístico como el de Cardona. En cuanto a los vestigios de la minería, aunque se preservan elementos de explotaciones anteriores, el concepto de patrimonio deja de considerarse mientras la mina está activa. Puesto que la minería en Súria significa empleo y riqueza, no existen perspectivas para potenciar una valorización patrimonial de la misma. Así pues, el diferente potencial patrimonial que presentan los dos sitios para favorecer un desarrollo alternativo, en la base del turismo cultural, constituye el primer factor diferenciador respecto de la valorización o rechazo de su herencia minera.

Hasta inicios del siglo xx, la explotación de la sal se realizaba a cielo abierto y de forma artesanal, en una cantera situada en el fondo occidental del valle, con lo cual la producción se mantenía a niveles relativamente bajos, y el impacto sobre el paisaje era reducido. Con el inicio de la extracción subterránea en 1902, el conjunto se empezó a transformar, dando lugar a un complejo sistema de galerías y pozos, complementados por castilletes, máquinas e instalaciones auxiliares. Pero la explotación en condiciones industriales comenzó realmente en los años treinta, con la instalación del depósito potásico de Cardona por la Unión Española de Explosivos, empresa química de origen catalán, más tarde denominada Ercros. El inicio de la explotación de la potasa marcó un cambio económico y social sin precedentes. Hasta entonces, la sal era explotada por el duque de Medinaceli, que mantenía la propiedad con una producción que no superaba las 3.500 toneladas anuales y que apenas ocupaba a treinta empleados, mientras la mayoría de la población trabajaba en la agricultura y en fábricas textiles. En 1923, la empresa compró los terrenos saliníferos y empezó a transformar el conjunto minero para su adaptación a un nuevo sistema de producción masiva. Abrió pozos y galerías y levantó una planta de cloruro potásico (Figura 4) y un teleférico para el transporte del mineral desde la mina. Además se construyeron viviendas para los trabajadores y los directores, y servicios como un hospital y una iglesia (Falguera, 2002). A partir de 1933, la extracción diaria alcanzó las 4.000 toneladas. El mineral pasaba a la fábrica de beneficio y luego a la estación de ferrocarril de Súria, desde donde era transportado al puerto de Barcelona para su exportación. La extracción de unas 38.000.000 toneladas entre 1929 y 1990 dio lugar a un total de 7.269.000 toneladas de potasa. Estos números se tradujeron en un notable crecimiento demográfico y mezcla cultural, debido a la llegada de trabajadores con sus familias desde toda España, en busca de un mejor futuro. La población de Cardona, que antes de la potasa alcanzaba unos 4.100 habitantes, en el periodo de mayor esplendor llegó a superar los 8.000 (1924-1930), de los que más de 1.500 se empleaban en la minería. La pequeña sociedad agraria y fabril de antes de los años veinte entraba en una nueva economía industrial, con perspectivas de riqueza y bienestar.

No obstante tales avances, la intensificación de la explotación para la obtención de la potasa afectó la fisonomía del Valle Salino de manera irreversible: las galerías superaban los 1.300 metros de profundidad y 300 kilómetros de longitud (Galera, 2005); los residuos potásicos se fueron acumulando en dos escombreras 
que alteraron sustancialmente la morfología del paisaje, y los materiales salinos percolaban hasta las aguas subterráneas e iban a parar al río Cardener, aumentando su salinidad (Font, 2005). Aun así, dado que en aquel momento todavía no se tenía conciencia de los impactos ambientales, la comunidad local recibió como una buena nueva el boom minero, que se traducía en empleo y crecimiento. Al mismo tiempo, especialmente en las primeras décadas del siglo, las duras condiciones laborales en la mina y los riesgos para la salud dieron lugar a las primeras huelgas. Valgan como ejemplos las huelgas en Cardona de 1929, la de "las nueve semanas" en 1931 o la revuelta anarcosindicalista de 1932 (Galera, 2005). La minería se convertía en un mal necesario que generaba nuevas controversias. Pero, a pesar de los problemas que suponía para la salud y el medioambiente, los beneficios económicos para las familias se impusieron, haciendo que la sociedad local apreciara la actividad minera como parte inseparable de su vida cotidiana.

\section{FIgURA 4 | Fábrica de cloruro potásico de la mina Nieves, en funcionamiento} desde 1926, situada en el barrio de La Coromina

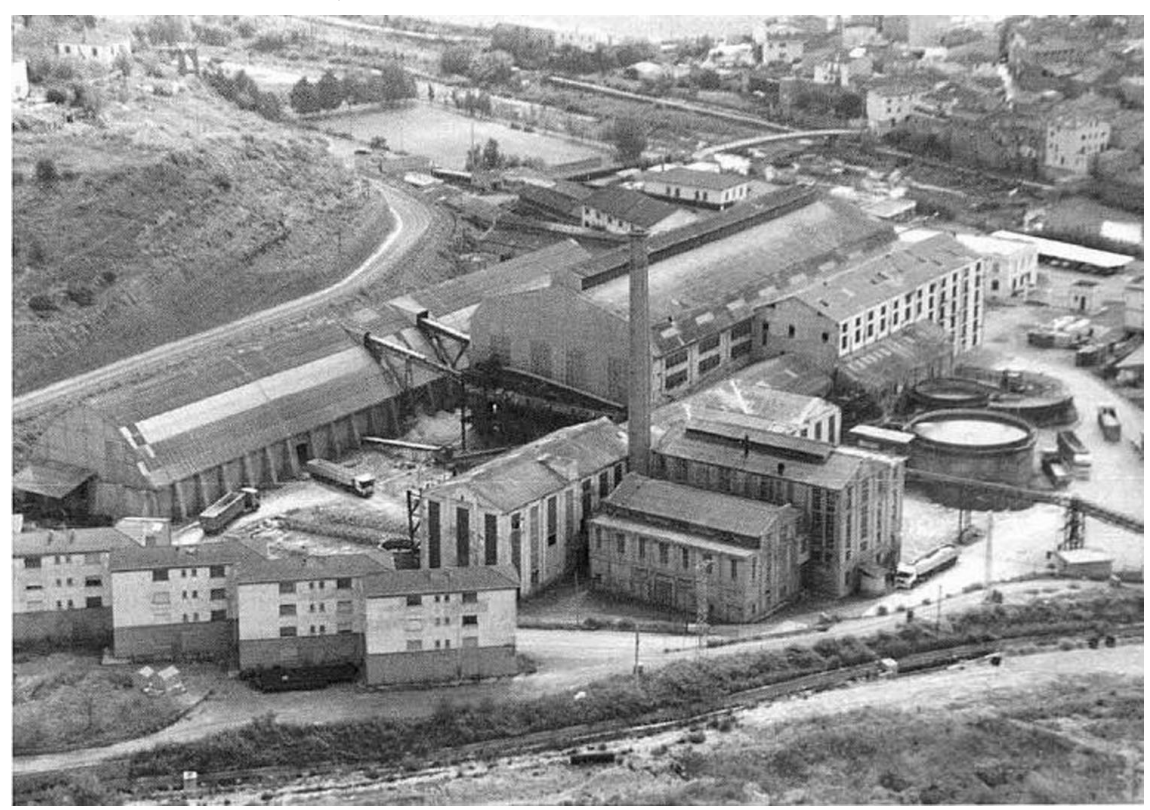

FUENTE: FALGUERA (2002)

La interrupción de la actividad minera de Cardona en 1990 tuvo un notable impacto en el municipio, que perdió de la noche a la mañana más de 500 empleos (Llurdés et al., 1999) y sufrió una notable recesión demográfica. De hecho, la población empezó a disminuir a partir de la segunda mitad del siglo xx, cuando la modernización y mecanización de la producción redujo la demanda de mano de obra, provocando la marcha de población en busca de mejores condiciones laborales. La desaparición definitiva de la actividad marcó una regresión del 10,9\% en el periodo 
pos-cierre (1990-1997), además del envejecimiento demográfico y la pérdida de la autosuficiencia laboral (Llurdés, 2017).

El agotamiento de la actividad minera, que hasta entonces se percibía como fuente de recursos, generó un gran trauma en la comunidad local. Sin embargo, la percepción del notable valor geológico del afloramiento salino ofrecía un nuevo impulso para la valorización patrimonial del conjunto. Y esto vino a contrarrestar el rechazo. La singularidad de la Montaña de Sal ya resultaba evidente para varios especialistas de la comarca, que en diversos momentos han defendido su protección. Es el caso del catedrático de la Universidad Politécnica de Catalunya y doctor en Geología por la Universidad de Barcelona J. M. Mata P. (com. pers., 12 de septiembre de 2019). Pero el aprecio creció cuando el Ayuntamiento impulsó el proyecto del Parque Cultural de la Montańa de Sal, inaugurado en 1997, con ayuda de aportes del Fondo Europeo de Desarrollo Regional (FEDER) y otras subvenciones públicas, cuya finalidad es la promoción turística de Cardona a través del reaprovechamiento de su patrimonio geológico y minero, convirtiéndolo en un equipamiento cultural.

La interrupción de la actividad minera de Cardona en 1990 tuvo un notable impacto en el municipio, que perdió de la noche a la mañana más de 500 empleos (Llurdés et al., 1999) y sufrió una notable recesión demográfica. De hecho, la población empezó a disminuir a partir de la segunda mitad del siglo xx, cuando la modernización y mecanización de la producción redujo la demanda de mano de obra, provocando la marcha de población en busca de mejores condiciones laborales. La desaparición definitiva de la actividad marcó una regresión del 10,9\% en el periodo pos-cierre (1990-1997), además del envejecimiento demográfico y la pérdida de la autosuficiencia laboral (Llurdés, 2017).

El agotamiento de la actividad minera, que hasta entonces se percibía como fuente de recursos, generó un gran trauma en la comunidad local. Sin embargo, la percepción del notable valor geológico del afloramiento salino ofrecía un nuevo impulso para la valorización patrimonial del conjunto. Y esto vino a contrarrestar el rechazo. La singularidad de la Montaña de Sal ya resultaba evidente para varios especialistas de la comarca, que en diversos momentos han defendido su protección. Es el caso del catedrático de la Universidad Politécnica de Catalunya y doctor en Geología por la Universidad de Barcelona J. M. Mata P. (com. pers., 12 de septiembre de 2019). Pero el aprecio creció cuando el Ayuntamiento impulsó el proyecto del Parque Cultural de la Montańa de Sal, inaugurado en 1997, con ayuda de aportes del Fondo Europeo de Desarrollo Regional (FEDER) y otras subvenciones públicas, cuya finalidad es la promoción turística de Cardona a través del reaprovechamiento de su patrimonio geológico y minero, convirtiéndolo en un equipamiento cultural.

La puesta en valor del conjunto de Cardona se ha visto favorecida por el crecimiento en las últimas décadas del turismo cultural y la ampliación del concepto de patrimonio, que hoy integra todos aquellos procedimientos que transforman el territorio. Al recordar el esfuerzo comunitario de épocas pasadas para poner la naturaleza al servicio del hombre, paisajes ordinarios y cotidianos se perciben como el legado de una comunidad, del trabajo y del estilo de vida que conforman la propia cultura. Se aprecian como lugares de memoria e identidad, y el reconocimiento de la estrecha relación entre cultura y paisaje abre el camino a la definición del concepto 
del paisaje cultural (Sabaté, 2010). En entornos mineros abandonados, esta idea ha empezado a tomar cuerpo en busca de respuestas a los numerosos problemas que representa el cierre de las explotaciones - proceso ocurrido en otros lugares en Espańa y en el resto de Europa a partir de los años sesenta-, para frenar pérdida de población, desempleo, degradación física y medioambiental, ausencia de incentivos para atraer nuevo desarrollo y tensión social. La conciencia del potencial para estimular un nuevo impulso hace que lugares hasta entonces rechazados por estar contaminados y degradados se empiecen a recuperar. Hacia los ańos sesenta aparecen unas primeras prácticas de puesta en valor a nivel internacional, y en España, hacia finales de los ańos setenta. Desde entonces, diversos conjuntos mineros son objeto de actuaciones en todo el país, que varían desde la redacción de inventarios, planes de restauración e intervenciones mínimas de corrección de los impactos, hasta iniciativas más complejas de reactivación y valorización del patrimonio. El Parque Cultural de la Montańa de Sal, inaugurado en 1997, es una de las primeras actuaciones de valorización del patrimonio minero que se llevan a cabo en Espańa, pocos años después de la apertura del pionero Museo Minero de Riotinto en Huelva (1988). El extraordinario afloramiento salino de la Montaña de Sal constituye el protagonista del conjunto y su mayor atractivo, apreciable por el visitante a través de una antigua galería de prospección de unos 250 metros de longitud (Llurdés et al., 1999). Esta se ha convertido en recorrido turístico y didáctico que da a conocer los pliegues y formas singulares del yacimiento, así como los procesos de explotación y el trabajo en las galerías (Figura 5). La recuperación patrimonial se extiende a la creación de una zona museística en las instalaciones del recinto minero, que interpreta la memoria histórica, incorporando antiguos edificios y máquinas rehabilitadas, un emblemático castillete que marca la entrada y un área museográfica al aire libre. El equipamiento se complementa con servicios al visitante: recepción, cafetería, tienda, espacio educativo para escolares y una zona de picnic. Desde el primer ańo de su funcionamiento (1997-1998) ha recibido un número de visitantes inesperado, que supera los 55.200, y actualmente alcanza una afluencia aproximada de 100.000 personas al año.

Debemos referirnos a la propuesta de Pere Riera para la recuperación del recinto minero de Cardona, presentada en 1990, justo después del cierre del mismo. En su proyecto de "La ciutat de la sal" (Riera et al., 1990), encargado por el Ayuntamiento, se contempla el aprovechamiento de la escombrera de la mina para integrar el proyecto en el paisaje y ampliar la oferta turística y cultural del municipio (Figura 6). La idea apareció como algo sumamente novedoso en su momento, dado que los residuos se perciben normalmente como un inconveniente para el paisaje, que debe ser eliminado. La montaña artificial dejada por la explotación de la potasa se considera parte de la actividad generada por la minería y testimonio del vigoroso pasado de Cardona. Así pues, en la propuesta de Riera, una vez impermeabilizada y recubierta para eliminar las sustancias contaminantes, la montaña se convertiría en una gran plataforma frente a la villa de Cardona, que acogería nuevos equipamientos culturales y turísticos compatibles con la puesta en valor del patrimonio minero. Aquella propuesta incluía un ámbito de actuación más amplio, que comprendía todo el valle salino, de una extensión que supera la cifra de 
1.500.000 metros cuadrados. Además del recorrido por el interior de la montaña, definía caminos que recuperaban antiguas rutas vinculadas con la explotación de la sal y vestigios de la minería, ofreciendo una percepción única del paisaje. Dichos caminos se complementarían con puntos de descanso, zonas ajardinadas y forestales, miradores y servicios al visitante, tales como bar, restaurante y zona de aparcamiento. Finalmente se descartó el proyecto, por su elevado coste y el poco compromiso de algunas administraciones (Llurdés, 2017).

\section{Figura 5 | La Montaña de Sal de Cardona: vista interior}

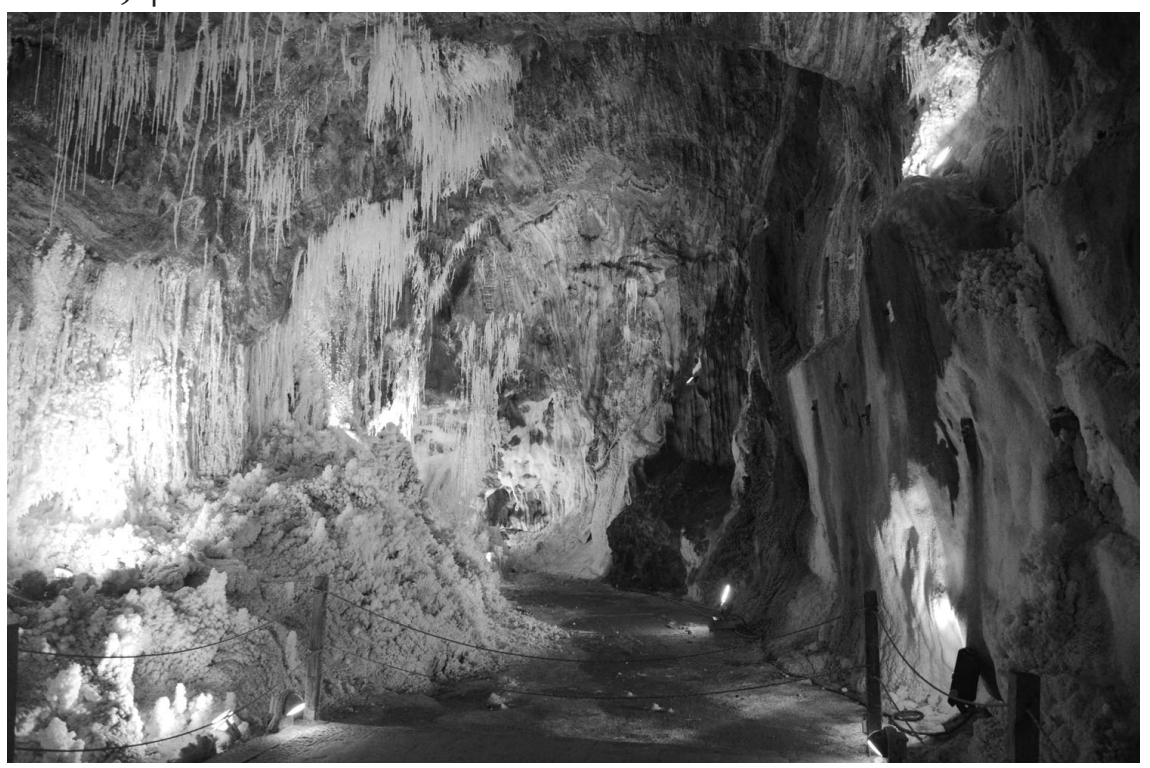

FUENTE: ARCHIVO PROPIO

No obstante haberse descartado, el proyecto aporta una interesantísima visión de futuro en torno a la valorización de espacios degradados que, por sus impactos transformadores, se suelen rechazar. Esta visión toma cuerpo en los últimos años a través de proyectos paradigmáticos que se han ido realizando en toda España. Destaca, entre otros, la transformación paisajística del antiguo vertedero del Garraf en Barcelona, un territorio de origen minero que se acabó usando como vertedero que contamina gravemente la zona. El proyecto se puso en marcha en 1999, desarrollado por los arquitectos Enric Batlle y Joan Roig. Tras una serie de operaciones para eliminar la contaminación, el paraje se convirtió en un paisaje agrícola integrado en el entorno del Parque Natural.

La belleza de la Montaña de Sal se reconoce desde antiguo, y se considera uno de los recursos paisajísticos más significativos de Cataluńa, que es tradicionalmente objeto de visita por interesados en la geología y el paisaje. El grabado que ilustra el viaje del francés Alexandre de Laborde, incluido en su Voyage Pittoresque et Historique de l'Espagne (1806-1820), una colección de los paisajes más destacados de 
la península, muestra este reconocimiento (Llurdés et al., 1999) (Figura 7). Las propias empresas mineras fueron las que incentivaron los primeros estudios y publicaciones (Larragan, 1923; Marín, 1923a, 1923b; Marín \& Rubio, 1914) sobre el afloramiento salino en la década de los veinte (Carreras, 2000). Sin embargo, excepto el interés de algunos especialistas y grupos de la zona por el valor geológico del yacimiento, la herencia dejada por la actividad minera no disfrutaba de ningún aprecio relevante en el momento en que se emprendía el proyecto patrimonial. Profundamente traumatizada por el cierre de la explotación, la comunidad local no mostró implicación relevante en la puesta en valor de este legado. Asimismo, siendo el patrimonio minero un concepto aún nuevo, resultaba difícil considerar ese lugar obsoleto como algo valioso.

\section{FIgURa 6 | Ilustración de la propuesta de Pere Riera para la "La ciutat de la sal”}

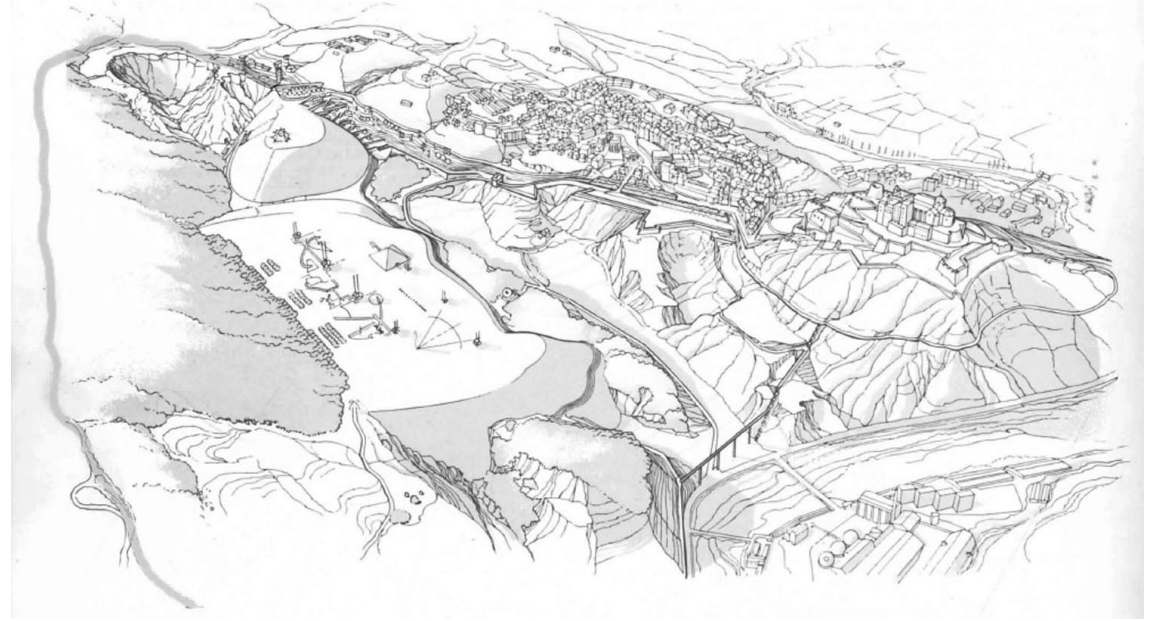

FUENTE: RIERA ET AL. (I990)

De todos modos, la promoción de este patrimonio como un nuevo motor de desarrollo derivado del turismo ha ido movilizando, a partir de entonces, diversas iniciativas culturales en el municipio y sus alrededores. Cardona cuenta actualmente con una amplia oferta turística y cultural, con la Montańa de Sal como eje vertebrador y elemento aglutinador de este potencial: visitas al castillo y al centro histórico medieval de la villa, rutas de senderismo o ciclistas por el entorno natural, actividades para familias o escolares, ferias y fiestas. Para reforzar este nuevo impulso, el Ayuntamiento constituyó en 2006 la Fundación Cardona Histórica, una fundación privada sin ánimo de lucro, que se dedica desde entonces a la recuperación y gestión de los recursos culturales del municipio. Además de la generación de ingresos, el creciente movimiento turístico genera empleos en los nuevos equipamientos, e incluso favorece la apertura de locales de restauración y alojamientos que suponen una actividad económica indirecta. Al mismo tiempo, han aparecido iniciativas particulares de creación de nuevos equipamientos que rescatan la cultura local salinera 
para su promoción turística. Destacan entre ellos el Museo de la Sal de Josep Arnau, cuya finalidad es la difusión de la tradición local del trabajo artesanal en sal a través de la obra de su fundador; el Taller Artesano de Sal, inaugurado en 1996 y dedicado a la fabricación de piedras y figuras terapéuticas; el centro de artesanía Art Sal, con su exposición permanente dentro del recinto del Parque Cultural de la Montaña de Sal, y otros pequeños negocios parecidos que se han ido montando dentro del pueblo. Analizando estas iniciativas, se puede reconocer una conciencia emergente en la comunidad local del potencial de su legado salinero para generar beneficios. Con ello se refuerza la autoestima y el orgullo de la gente de Cardona por su pasado minero, que motiva a defenderlo.

\section{figura 7 | Grabado de Cardona y la Montaña de Sal por Alexandre de Laborde en su obra Voyage pittoresque et historique de l'Espagne (1806-1820)}

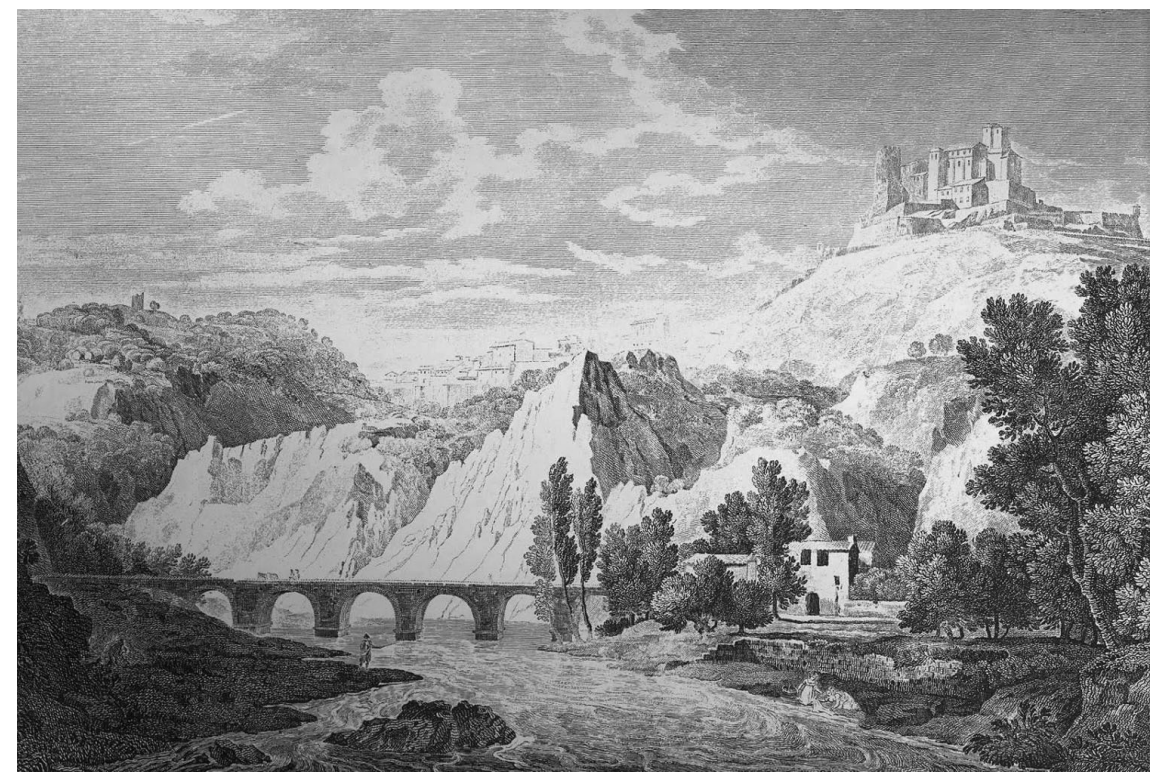

FUENTE: LES PEDRES DE CATALUNYA. EN: HTTPS://LESPEDRESDECATALUNYA.BLOGSPOT.COM/2OI 6/O4/ SANT-VICENC-DE-CARDONA.HTML

\section{Cardona y Súria: alternativas contrapuestas en dos paisajes mineros vecinos}

La explotación de la potasa afecta el entorno natural de Cardona. Además de la elevada salinidad de las aguas, existen dos grandes escombreras que alteran el paisaje del valle, conocidas como Terrera Vella y Terrera Nova. Pero, al contrario que en Súria, donde la gigantesca montańa artificial sigue creciendo mientras Iberpotash-ICL aumenta la producción, las escombreras de Cardona han sido objeto de restauración. En 2001, Ercros firmó un convenio con el Ayuntamiento y la Generalitat de Catalunya para el tratamiento de las escombreras mediante la obtención de cloruro 
sódico a partir de los residuos potásicos para su uso industrial, y la reforestación de los espacios que se fueran liberando. Para ello se instaló en el lugar una planta de procesamiento, la Fábrica de Cardona, que ocupaba a 34 trabajadores. Con este método, se consiguió eliminar las escombreras y su impacto visual sobre el paisaje y, al mismo tiempo, reducir las sustancias salinas que habían ido contaminando la cuenca del río Llobregat. Así pues, la restauración minera se llevó a cabo a través de una nueva actividad industrial compatible con el entorno, que contribuyó a la restauración y protección del paraje natural del Valle Salino. En 2012 se finalizó la explotación de la Terrera Nova y actualmente está en proceso la revegetación de los terrenos liberados por su desaparición, según el plan aprobado por la Dirección General de Calidad Ambiental y Cambio Climático (DGCA) de la Generalitat de Catalunya (Ercros, 2019, pp. 26-33, 62-64). La explotación de la Terrera Vella comenzó en 2008 pero se interrumpió en 2017, cuando la empresa se obligó a cerrar la fábrica de Cardona después de las nuevas restricciones europeas en el proceso de producción de cloro (Figura 8). La restauración de aquella escombrera resultó más complicada a causa de la acumulación de sustancias ajenas, además de salinas en las décadas anteriores, y por la falta de normativa respecto a la gestión de los residuos mineros (J. M. Mata P., com. pers., 12 de septiembre de 2019). Sin embargo, Ercros presentó a la DGCA un plan actualizado en 2017, en el cual proponía un tratamiento alternativo de la Terrera Vella que, por un lado, garantizaría la gestión de las aguas superficiales afectadas por los residuos salinos; y por otro, posibilitaría un futuro uso del depósito salino que todavía contiene. Además de rehabilitar las escombreras, Ercros se ocuparía de la impermeabilización de las zonas inestables del Valle Salino para reducir la salinización de las aguas de la cuenca.

FIGURA 8 | La escombrera vieja de Cardona en proceso de restauración (2017)

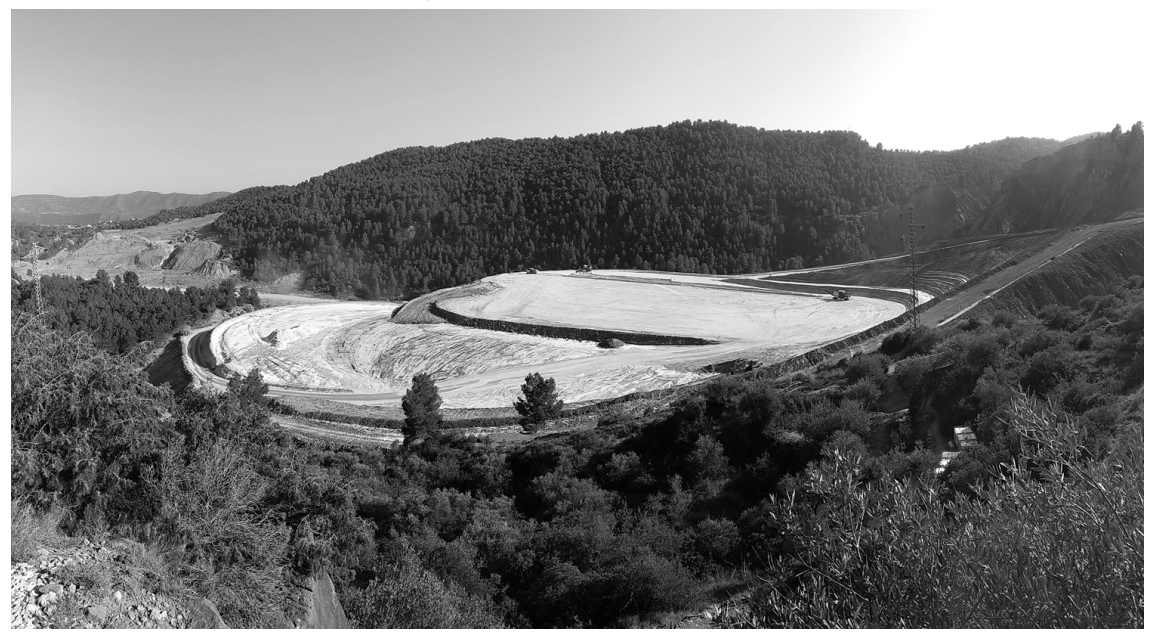

FUENTE: ARCHIVO PROPIO

Se puede concluir que, tratándose de una empresa local, arraigada al lugar, Ercros muestra una cierta sensibilidad por los impactos que su actividad genera sobre el 
paisaje de Cardona. Al tener una tradición industrial centenaria en el territorio catalán, y estar integrada por socios nacionales, es más respetuosa en términos de medioambiente, seguridad laboral y salud. Al concluir su actividad extractiva en Cardona, se ocupó del tratamiento de los terrenos afectados, acorde con la normativa ambiental y en colaboración con las administraciones locales y entidades académicas. Además del convenio con el Ayuntamiento y la Generalitat, de 2001, para la recuperación del Valle Salino, firmó un contrato con las universidades de Barcelona (Universitat Politècnica de Catalunya [UPC] y Universitat de Barcelona [UB]) para el asesoramiento técnico en la redacción del plan de restauración de la Terra Vella.

Por otro lado, la realidad en Súria es totalmente diferente. La multinacional ICL-Iberpotash sigue explotando intensamente el depósito potásico de la mina de Cabanasses; y, sin tomar medidas adecuadas para la gestión de los millones de toneladas de residuos salinos que se continúan acumulando en la gigantesca escombrera, amplía sus instalaciones para incrementar la producción. Esto desvela otro factor que incide en la valoración o degradación de un territorio minero, que es el origen de las empresas explotadoras. Mientras la mina de Cardona siempre ha sido de propiedad local, la de Súria pasa pronto a manos extranjeras, haciendo que la manera en que la actividad repercute sobre el entorno natural del Bages sea totalmente diferente. Con la adjudicación de las primeras concesiones en 1918, los derechos del yacimiento de Súria pasaron a la multinacional belga Solvay, que en aquel momento desarrolla su actividad industrial en varios países, entre otros Estados Unidos y Rusia (Galera, 2005). Solvay constituye la empresa Minas de Potasa de Súria, S.A. y explota la Cuenca Potásica Catalana desde 1920 hasta 1982, cuando el yacimiento pasa a manos del Estado por un tiempo limitado, formando parte del Instituto Nacional de Industria (INI), hasta que en 1998 adquiere los derechos la actual propietaria ICL-Iberpotash, filial de la compañía israelí ICL. Con una facturación de 6.300 millones de euros anuales, es líder en la producción de fertilizantes y sexto productor mundial de potasa (Martínez, 2018). Siendo una empresa multinacional, totalmente desarraigada del lugar, su única prioridad es obtener la máxima rentabilidad posible de la explotación. Por ello no muestra ninguna preocupación por la incidencia de su actividad sobre el medioambiente y la salud de las personas, ni repara en contaminar el territorio para incrementar su beneficio. Bajo estas circunstancias, la escombrera de Súria acumula actualmente más de 26 millones de toneladas de residuos salinos que superan las 40 hectáreas de superficie (Figura 9). Y si ello fuera poco, Iberpotash amplía sus instalaciones en Súria para aumentar la producción, mientras la demanda internacional de la potasa va creciendo, tanto por la necesidad elevada de fertilizantes, como para su uso en la fabricación de explosivos y otras aplicaciones. En 2012 se llevó a cabo el proyecto Phoenix, una inversión de millones de euros para la construcción de una rampa de extracción de 4,5 km que permite la explotación a 900 metros de profundidad (Figura 10), además de nuevas plantas para el aprovechamiento de los residuos salinos (Roig et al., 2017). Con el plan de ampliación, la gigantesca montaña artificial de Súria puede alcanzar los 100 millones de euros anuales en 2075 (Badia, s.f.). 
FIGURA 9 | La escombrera de Súria, que todavía sigue creciendo

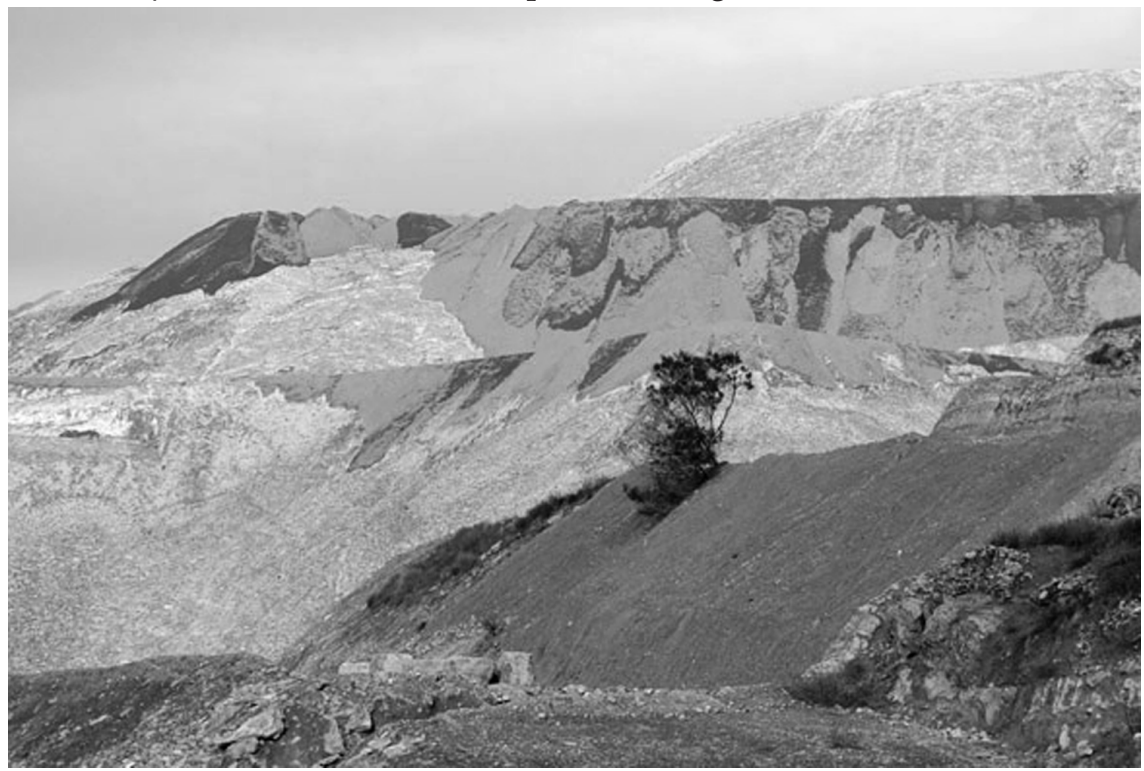

FUENTE: ALERTA MINERA. HTTP://ALERTAMINERA.BLOGSPOT.COM/2OI6/O2/LA-JUSTICIA-CATALANA-DALA-RAZON-LA.HTML\#.XORDZOGZAM9

Los habitantes de la comarca no permanecen indiferentes frente a las consecuencias de la potasa sobre el medioambiente y su propia salud. Pese a que, hasta hace poco tiempo, los impactos ambientales de las actividades industriales no eran considerados, en los últimos ańos ha aparecido una creciente concienciación sobre los mismos, lo que genera incertidumbre y conflictos. Los cambios en el paisaje del Bages y la contaminación del agua, a causa de la actividad descontrolada de Iberpotash, se han convertido en objeto de polémica entre colectivos ecologistas y grupos vecinales ante la empresa y las administraciones locales y autonómicas. Estas reacciones se traducen en continuas denuncias y sentencias judiciales contra la multinacional que se han ido dictando hasta la fecha, obligando a la eliminación de los residuos y al pago de indemnizaciones por los daños provocados. No obstante, siendo la industria más importante del Bages, que ofrece empleo a más de 1.200 trabajadores en Súria y genera un total de 4.000 empleos directos e indirectos, la empresa recibe el apoyo de las administraciones y de algún sindicato. Teniendo este apoyo institucional, de la administración y de los trabajadores, y aprovechando de los vacíos de la normativa vigente, consigue escapar de sus obligaciones respecto a la restauración ambiental, creciendo a la vez la rentabilidad de su centro. Así pues, el dominio de Iberpotash deja en la comarca una inmensa hipoteca en forma de montańas artificiales; y la salinización del Llobregat, derivada de esta actividad minera, sigue siendo el factor principal de la mala calidad del agua de Barcelona. 
Figura io | Vista interior de la mina de Cabanasses, en Súria

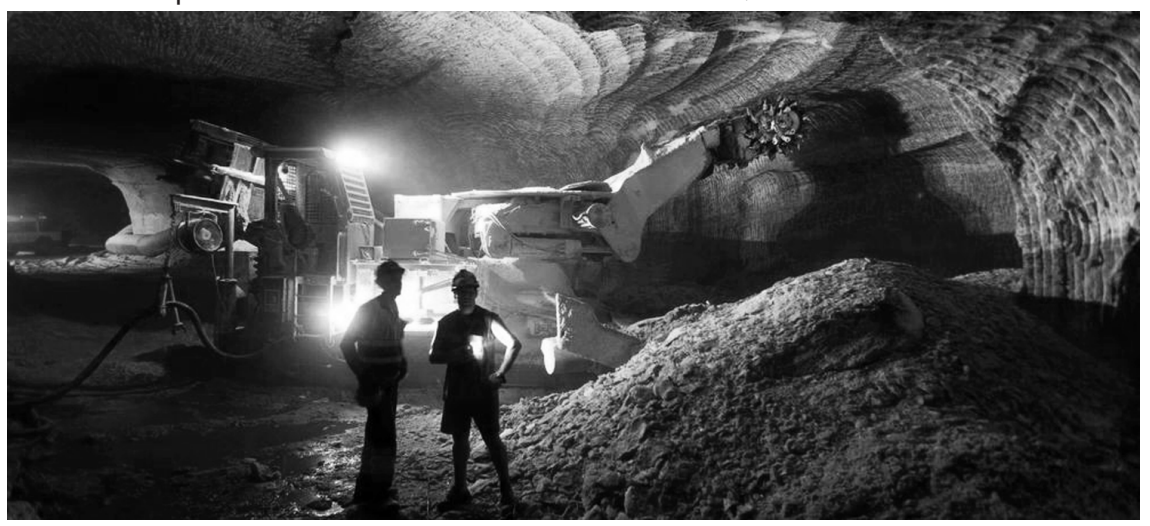

FUENTE: MINAS DE SÚRIA (2OI2). HTTPS://DIARIOI6.COM/LA-EXPLOTACION-LA-POTASA-CATALUNYAUNA-FIEBRE-DEL-PASADO-AMENAZA-TERRITORIO-PRESENTE/

Se han realizado algunas medidas correctoras, como la construcción de un colector de salmueras en 1990 para mejorar la calidad del agua del río Llobregat, pero no resultan suficientes para impedir la contaminación. Este colector consiste en dos conducciones situadas a lo largo de las cuencas que recogen los lixiviados mineros de las escombreras. Sin embargo, debido a la alta cantidad de residuos, resulta insuficiente para resolver el problema. La necesidad de desalar las aguas para su uso doméstico y agrícola supone un sobrecoste de 300 millones de euros, que repercute económicamente en la comunidad local (Martínez, 2018). En el contexto de la obligación de adaptarse a la nueva normativa europea de minería sostenible, que impide el uso de mercurio en la producción de potasa, Iberpotash incluye en su plan de ampliación la construcción de plantas de producción de sal vacuum a partir de los residuos salinos, para su aplicación en la industria química, lo que reduciría el volumen de las escombreras. Aun así, considerando los millones de residuos que quedan por tratarse, este método tardará muchísimos años en surtir efecto. Si bien algunas de las prácticas implementadas aportan una paliación parcial de los impactos, estos siguen existiendo en la misma medida en que la actividad minera persiste.

Otro factor que incide en que la gravedad de los impactos de la potasa sea tan diferente en los dos municipios considerados es la extensión de cada explotación. En el caso de Cardona, la explotación finaliza en los años noventa y no llega a tener la expansión que alcanza la de Súria, lo que supone una producción de residuos mucho más reducida. La extracción de sal gema en los siglos anteriores se realizaba a cielo abierto y de forma artesanal, por lo que la incidencia sobre el ambiente era mínima. La explotación de la potasa dura seis décadas, y la Montaña de Sal llega a acumular un total de 7.269 millones de toneladas de potasa, mientras la producción anual de Iberpotash en Súria llega actualmente a un millón de material y pronto se va a incrementar. Respecto a las escombreras, la Terrera Nova de Cardona ya se ha eliminado, y aunque la restauración de la escombrera vieja no se ha completado, su incidencia no es comparable con las de Súria y Sallent, dado que su volumen actual no supera los cinco millones de toneladas, y su tratamiento ya está planificado. 
Se suma a lo anterior la distinta topografía de los dos municipios, que a su vez repercute en el grado de contaminación de cada explotación. Cardona está ubicada en altura, en la cabecera de la comarca, con lo que las sustancias salinas que contaminan las aguas se trasladan a los municipios situados río abajo. Súria, en cambio, situada en una posición frágil en medio del valle del río Cardener y atravesada por el mismo, queda expuesta a los impactos de la actividad extractiva y no tiene la misma capacidad para evitarlos. Mientras la presencia de sustancias salinas en el Cardener es reducida en Cardona, Súria sufre un incremento de salinidad del agua del río de manera que no puede utilizarla para uso doméstico.

Por último, cabe hacer hincapié en el papel que desempeñan los agentes locales en el impulso de un nuevo desarrollo local a través del patrimonio. En cuanto cierra la mina de Cardona, tanto las administraciones como los grupos locales reconocen el potencial turístico de los recursos naturales y culturales de su territorio e impulsan su puesta en valor para detener la regresión económica. El Ayuntamiento impulsa la redacción del proyecto y obtiene subvenciones para ponerlo en marcha, lo que con los años contribuye al rescate de la cultura salinera local, incrementando a su vez la autoestima de la comunidad y haciéndole partícipe en el proceso de valorización. En Súria, en cambio, las administraciones locales cierran los ojos a la actividad incontrolada de Iberpotash sobre el medioambiente y la salud de la población, poniendo el interés económico por delante del bien común. Con esto se hace constar que la tolerancia de las administraciones locales y autonómicas ante la irresponsabilidad de Iberpotash en sus obligaciones ambientales muestra una cierta falta de poder político capaz de defender el bien común frente a los intereses de los grandes inversores.

\section{A modo de conclusión: ¡algunos paisajes mineros son más valiosos que otros?}

En la investigación en curso hemos comparado dos modelos contrapuestos de identificación entre la población y las actividades mineras que desarrolla, en dos localidades vecinas en la comarca del Bages.

En el primero (Cardona) se afronta la crisis derivada del cierre de la explotación con un proyecto patrimonial que permite recuperar autoestima y empleos.

En el segundo (Súria), cuestiones como el medioambiente o la salud se sacrifican en aras de maximizar el beneficio.

¿Cuáles son los factores que condicionan el rechazo o valorización patrimonial del paisaje minero?

En el caso de Cardona podemos reconocer una cultura milenaria y, por tanto, largamente arraigada. Se trata de una actividad compartida desde tiempos inmemoriales por la población local, realizada inicialmente de forma artesanal. Cuando incrementa su importancia, arranca con una empresa local que crece y en la cual tiene participación el Estado. La población está plenamente identificada con su mina y su Montańa de Sal. Los inconvenientes que esta genera, los desechos y la salinización del río, adquieren rasgos escultóricos en el paisaje o se producen aguas abajo. Cardona, villa ducal, que alcanzó notoriedad en la Corona de Aragón, alberga una colegiata del siglo xi y un castillo de origen románico, que resistió a 
Napoleón y fue el último reducto frente a las tropas de Felipe V. La larga tradición cultural y el carácter emprendedor de su población es un caldo de cultivo adecuado para que surja de la misma sociedad local el impulso para reactivar la economía a partir de un proyecto de puesta en valor de sus recursos patrimoniales vinculados a la explotación de la sal.

En cambio, en Súria, frente a la trascendencia de los puestos de trabajo, los elevados impactos ambientales pasan a segundo plano y, en cierta medida, se acaban tolerando. Tratándose de un municipio pequeño y alejado de los grandes centros de actividad, sin otras alternativas de desarrollo, la comunidad confía su bienestar a la minería, y la percibe como algo positivo. La actividad pasó bien pronto a manos extranjeras, de una de las principales empresas a nivel mundial, y con un centro de decisión alejado del lugar y totalmente ajeno a la situación local. La administración, que debiera velar por aplicar con rigor la legislación y evitar la degradación ambiental, ha transigido frente a la considerable dimensión de la actividad y la velada amenaza que se cierne sobre un considerable número de empleos.

Cardona superó la crisis derivada del cierre de la mina apoyándose en su patrimonio milenario. Defiende su memoria y cultura salinera con su Montaña de Sal. En un contexto donde el sector salino ha perdido su protagonismo, la puesta en valor de los recursos geológicos y mineros dan impulso al desarrollo local. El rico patrimonio cultural y natural y la centenaria tradición salinera; el arraigo de la empresa explotadora y la menor gravedad de los impactos ambientales de la potasa, además de la capacidad de los agentes locales para desarrollar un proyecto de Parque Cultural, devienen esenciales. Se suscita una clara complicidad entre la comunidad y el paisaje minero que ha construido secularmente.

El análisis del devenir de estos dos paisajes de la potasa, tan cercanos y tan distantes en su evolución, con impactos y relación con su población tan diferentes, nos lleva a reconocer cuánto inciden diversos factores en la recuperación de los paisajes mineros. De hecho, ratifica una interpretación deducida en anteriores estudios, según la cual "lo más importante en el arranque de los proyectos es reforzar la autoestima de los residentes (...) los visitantes, museos e inversiones ya vendrán después. En cambio, sin base local, sin iniciativas de los mejores conocedores de un territorio, no hay éxito posible" (Sabaté, 2004, p. 24).

Entre tantas actividades que transforman drásticamente el paisaje, existen grados de repercusión diferentes, en función de las características particulares de cada explotación. En el caso de la potasa, los impactos generados no alcanzan seguramente los niveles de las minas de carbón, asbesto o mercurio. Lo que provoca el rechazo es la práctica de la empresa explotadora y la ausencia de control para atenuar el impacto. La gestión de las explotaciones mineras, la propia actitud de los agentes implicados, afectan fundamentalmente la percepción de la actividad, su aprecio o rechazo.

En cualquier caso, el cambio que están generando en estas últimas décadas proyectos como el de la Montaña de Sal en la percepción de los espacios degradados, alimenta expectativas de recuperación futura de las escombreras. Incluso a pesar de su considerable impacto ambiental, se empiezan a aceptar como parte del paisaje y fruto de una actividad tradicional que genera recursos, tangibles e intangibles, susceptibles de alimentar un proceso de valorización. 
Aunque queda aún mucho camino por delante, existen en España diversos ejemplos en que las escombreras han sido objeto de tratamiento y, una vez atenuada la contaminación, se integran en el proyecto de recuperación. Entre las prácticas más comunes están las dedicadas a la rehabilitación ecológica o paisajística, que acaban conformando nuevos espacios naturales, agrícolas o forestales, posibilitando además la introducción de nuevos usos compatibles con el entorno donde se sitúan. Destacan como ejemplos la rehabilitación en las canteras de Los Yesares y de Río de Aguas en Sorbas (Almería), la rehabilitación de la escombrera de la mina de As Pontes en Coruña, el acondicionamiento de las escombreras en las minas de Almadén para dar lugar al Parque Minero, etcétera (Fernández, 2006). También resulta interesante mencionar los trabajos de investigación iniciados en 1998 en el ámbito académico de la UPC dedicados al estudio de las posibilidades morfológicas de las escombreras de Súria. En el contexto del curso "Los paisajes del desecho, su recuperación. Proyectar con la sal", se elaboran propuestas que establecen un programa de uso mínimo, con accesos, caminos, terrazas y miradores, y otras que fomentan una percepción visual del depósito como un objeto singular en el paisaje (Rosell, 2002). Estas tendencias abren el camino para el aprovechamiento de las escombreras del Bages, ofreciendo alternativas más viables que las hasta ahora acostumbradas.

Por último, vale la pena hacer hincapié en la declaración del Geoparque de la Cataluña Central en 2012, que da lugar a propuestas de valorización del patrimonio geológico y minero. Tanto la Montaña de Sal como la explotación de Súria están integradas en dicho Geoparque, lo que denota el aprecio por los recursos geológicos y mineros de la zona. Siendo la cuenca potásica catalana una de las más relevantes de su tipo a nivel mundial y una de las reservas más importantes de Europa, la iniciativa del Geoparque puede contrarrestar el rechazo debido a la degradación causada por la actividad minera y fomentar nuevas oportunidades basadas en el patrimonio acumulado. Especialmente en Súria, que de momento no cuenta con recursos turísticos relevantes, la promoción del Geoparque constituye un valor ańadido. Tanto la explotación minera, como las interesantes formaciones geológicas, se integran en rutas turísticas que dan a conocer sus valores.

Llegamos, pues, a la conclusión de que, cuando un paisaje geológico y minero es identificado como recurso cultural -aunque sea radicalmente transformado y degradado-, ello permite impulsar su puesta en valor. O, como se ha concluido en estudios anteriores, que "la gestión inteligente de los recursos patrimoniales está suponiendo en diversos territorios uno de los factores clave para su desarrollo económico, porque atrae turismo e inversiones, genera actividades y puestos de trabajo, pero muy fundamentalmente, porque refuerza la autoestima de la comunidad" (Sabaté, 2004, p. 8).

\section{Agradecimientos}

Este trabajo debe ser reconocido como una labor conjunta realizada con mi coordinador de tesis Joaquín Sabaté, a quien le debo mis más sinceros agradecimientos. El artículo forma parte de una investigación más amplia que venimos desarrollando conjuntamente desde hace ya unos años, en torno a la recuperación de los paisajes 
culturales mineros. Ambos hemos abordado el tema conjuntamente desde el inicio, en la selección de casos, enfoque y redacción, habiendo intercambiado el texto para irlo ajustando y aportando visiones complementarias de manera continua.

\section{Referencias bibliográficas}

Badia, J. (sin fecha). El medi natural del Bages. Els impactes ambientals. MontSalat. https:// ichn2.iec.cat/Bages/impactes/imatges\%20grans/cSuria.htm

Carreras, J. (2000). Geozona 217 Cardona - Muntanya de la Sal. Generalitat de Catalunya, Departament de Medi Ambient i Habitatge, Direcció General del Medi Natural. http://mediambient.gencat.cat/web/.content/home/ambits_dactuacio/patrimoni_ natural/sistemes_dinformacio/inventari_despais_dinteres_geologic/consulta_de_les_ fitxes_descriptives_dels_eig/documentos/217_descrip.pdf

Casas, J. M. (2016). Iberpotash tardará medio siglo en eliminar su montaña de sal. Economía

Digital. https://www.economiadigital.es/directivos-y-empresas/iberpotash-tardaramedio-siglo-en-eliminar-su-montana-de-sal_182649_102.html

Catà, J. (2018, febrero 15). La uE da un ultimátum a Espańa por la contaminación del aire en Madrid y Barcelona. Europa Press. http://www.europapress.es/sociedad/medioambiente-00647/noticia-ue-da-ultimatum-espana-contaminacion-aire-madridbarcelona-20170215141303.html

Ercros. (2019). Informe de responsabilidad social empresarial 2018. Ercros, S.A. http://www.ercros. es/index.php?option=com_content\&view=article\&id=570\&Itemid=682\&lang=es

Falguera, T. S. (2002). El passat mineroindustrial de la conca potassica de Catalunya. Dovella. Revista Cultural de La Catalunya Central, (75), 5-14. Manresa: Centre d'Estudis del Bages. https://core.ac.uk/download/pdf/38987072.pdf

Fernández, M. R. (2010). La cuenca salina del Bages y la calidad del agua del río Llobregat. Macla. Revista de la Sociedad Española de Mineralogía, (12), 62-63. http://www.ehu. eus/sem/macla_pdf/macla12/Macla12_62.pdf

Fernández, R. R. (Ed.). (2006). Rehabilitación de espacios mineros. Experiencia española. Fundación Conama. http://www.conama9.conama.org/conama9/download/files/ GTs/GT_MIN//MIN_final.pdf

Fíguls, A., Weller, O., Grandia, F., Bonache, J., González, J. \& Lanaspa, R. M. (2013). La primera explotación minera de la sal gema: La Vall Salina de Cardona (Cataluña, España). Chungará. Revista de Antropología Chilena, 45(1), 177-195. https://doi. org/10.4067/S0717-73562013000100009

Font, J. (2005). Comportament de l'aigua subterrània a la vall Salada de Cardona. Tesis doctoral. Departament d'Enginyeria Minera i Recursos Naturals, Universitat Politècnica de Catalunya. https://www.tdx.cat/handle/10803/6989

Galera, A. (2005). La búsqueda y explotación de la potasa en Cataluña. El Parque Cultural de la Montaña de Sal (Cardona, Bages) y la reinterpretación de su historia. De Re Metallica, (4), 39-57. https://dialnet.unirioja.es/servlet/articulo?codigo $=4602095$

Larragan, A. (1923). Datos acerca de los sondeos realizados en la cuenca potásica de Cataluńa. Boletín GEA, Instituto Geológico y Minero de España (IGME), 64, 103-210. 
Llurdés, J. C. (2017). El paisaje minero, ¿patrimonio o incoveniente paisajístico?: El caso de la comarca del Bages (Barcelona). Ería, Revista Cuatrimestral de Geografía, 37(2), 151167. https://dialnet.unirioja.es/servlet/articulo?codigo $=6192067$

Llurdés, J. C., Saurí, D. \& Cerdán, R. (1999). Conflictos locacionales en territorios en crisis: Turismo y Residuos en Cardona (Barcelona). Anales de Geografia de La Universidad Complutense, 19, 119-140. https://revistas.ucm.es/index.php/AGUC/article/view/ AGUC9999110119A

Marín, A. (1923a). Investigaciones de la cuenca potásica de Cataluña. Boletín GEA, Instituto Geológico y Minero de Espańa (IGME), 44, 3-78.

Marín, A. (1923b). La potasa. Boletín GEA, Instituto Geológico y Minero de España (IGME), 28, 113-127.

Marín, A. \& Rubio, C. (1914). Sales potásicas de Cataluña. Boletín GEA, Instituto Geológico y Minero de España (IGME), 34, 3173-230.

Martinez, A. J. \& Waldron, T. (2015). Potasas del Llobregat in Catalonia, Spain. Environmental Justice Atlas. https://ejatlas.org/conflict/potasas-del-llobregat-catalonia

Martínez, C. D. (2018, noviembre 27). La explotación de la potasa en Catalunya. Una "fiebre" del pasado que amenaza el territorio presente. Diario16. https://diario16.com/laexplotacion-la-potasa-catalunya-una-fiebre-del-pasado-amenaza-territorio-presente/

Riera, P., Parcerisas, J. \& Gutiérrez, J. (1990). La ciutat de la sal. Pla especial de protecció i millora de la muntanya de sal de Cardona i de la vall salina. Ajuntament de Cardona. Diputació de Barcelona.

Roig, I., Campeny, M., Alfonso, P., Boix, L. \& Font, M. (2017). Al punt de sal. Ajuntament d'Arenys de Mar, Catalunya. https://upcommons.upc.edu/bitstream/ handle/2117/114880/Al+punt+de+sal.pdf?sequence=1

Rosell, Q. (2002). Las salinas de Súria, Bages, España. En Después de = Afterwards. Rehacer paisajes. Remaking landscapes (pp. 96-97). Gustavo Gili.

Sabaté, J. (2004). Paisajes culturales. El patrimonio como recurso básico para un nuevo tipo de desarrollo. Urban, (9), 8-29. http://hdl.handle.net/2117/9867

Sabaté, J. (2010). De la preservación del patrimonio a la ordenación del paisaje: intervenciones en paisajes culturales (Europa - Latinoamérica). Revista Labor e Engenho, 4(1), 10-25. https://doi.org/10.20396/lobore.v4i1.1686 
